UDC: $811.111 ' 271.16: 004.738 .12 \quad$ https://doi.org/10.22190/JTESAP2101119K

Original scientific paper

\title{
LEARNING BEHAVIOUR IN AN EXTRAORDINARY SITUATION
}

Žana Knežević, Vesna Tripković-Samardžić

Faculty of Foreign Languages, University “Mediterranean” Podgorica, Montenegro

\begin{abstract}
Closures of higher educational institutions and cancellation of in-person classes caused by COVID-19 made ESP teachers in Montenegro find alternative ways to transform the serious emergency into an important opportunity to foster innovation in the area of teaching ESP online. Doing so, the teachers sought to enhance the experience already in place in many countries round the world. This paper deals with students' responsiveness to employing new teaching methods aimed at increasing learner autonomy in virtual environment during COVID-19 pandemic, which inevitably encouraged the use of technology. The study focuses on two groups of students (19 second-year students of the Faculty of Visual Arts and 43 thirdyear students of the Faculty of Information Technology, University Mediterranean Podgorica, Montenegro) and their response to the alternative methods of teaching ESP, as well as the results they achieved in mid-term and final exams. The results are compared to those that the same group of students achieved in the previous semester, providing a comparative analysis of an impact of online teaching on students' learning behaviour and accomplishments in the extraordinary situation.
\end{abstract}

Key words: extraordinary situation, COVID-19, performance, academic participation, learning behaviour

\section{INTRODUCTION}

Since 11 March 2020, the COVID-19 pandemic, one of the most severe global crises in our history, has exerted the most devastating direct physical impact and economic effects worldwide, with the new upsurge of violence, particularly affecting Europe (Žižek 2020). The pessimistic reports on the effects of the crisis on the education system confirm the disastrous effects of the school closures, stating that it has been "the largest disruption of education systems in history" (United Nations 2020,2) having impacted 94 per cent of the world's student population. On the other hand, global cooperation and solidarity spurred by the crisis and the innovations in the education sector stimulated by the need to enable education continuity speak in favour of the positive effects of the pandemic.

Despite difficulties that might arise from online teaching (poor preparedness for the usage of Learning Management Systems, theoretical online content, the lack of practice and effective learning, the lack of community, low-quality course content, technical problems, differences in learner's capability, willingness to adapt to online teaching, their confidence

Submitted November $4^{\text {th }}, 2020$, accepted for publication November $12^{\text {th }}, 2020$

Corresponding author: Žana Knežević. University "Mediterranean" Podgorica, Montenegro

|E-mail: zana.knezevic@unimediteran.net 
level and time management), the advantages of online education in any extraordinary situation vastly outweigh any disadvantages (Dhawan 2020). In addition to the benefits usually associated with online learning (accessibility, affordability, flexibility, its potential to increase the learning potential of students and promote life-long learning), crises bring other benefits and strengths of online teaching into focus such as: the potential to cater to the needs of a wide audience, student-centeredness, collaborative learning environment and a huge variety of content aimed at producing a human touch to the lectures and providing immediate feedback (Dhawan 2020). As "the panacea for the crisis" (Dhawan 2020, 7), online teaching has become a necessity for all academic institutions. New distant learning solutions have brought about the change in teaching-learning approach, but have also raised our awareness of the crucial role of teachers in delivering quality online education (United Nations 2020).

The purpose of this paper is to explore whether and to what extent different teaching approaches employed in the virtual classroom (online teaching) during COVID-19 have brought about the positive changes in students' learning behaviour.

\section{ONLINE LEARNING DURING COVID-19 At Higher EdUCATION INSTITUTIONS IN MONTENEGRO}

On 13 ${ }^{\text {th }}$ March 2020 the Government of Montenegro proclaimed the first set of measures related to COVID-19 crisis. All educational institutions were temporarily closed for 15 days, and the situation became a challenge for the whole educational system. Higher education institutions offered students an electronic service for enabling quick access to email and online lectures through Moodle platform. It was recommended that the teachers at these institutions organize classes in several ways: 1) by uploading the teaching material on the official website, 2) by uploading multimedia presentations on the Moodle platform, and 3) by using Zoom application.

On 26 March, the teaching staff at the University "Mediterranean" Podgorica, was given the first set of teaching and learning instructions to be used during the confinement. They were instructed to adapt to a certain extent to the changed study policies, modify their courses to suit the virtual environment, that is apply different teaching approaches and modes of assessment, and were encouraged to use the Zoom application for learning experience in synchronous environment, i.e. one which enables students to attend live lectures, have real-time interactions with instructors and other learners as well as an instant feedback (Dhawan 2020). Most of the teachers and students found it quite easy to use Zoom, and quickly took advantage of its tremendously useful features including: a) video sessions for at least 50 students, b) screen sharing during a call, c) the possibility of recording the lectures, d) on-screen whiteboard, e) live video chat to keep the sessions dynamic, e) the possibility to join from any device, etc. Given that the University has been using Moodle learning platform as a form of asynchronous learning environment in which "learning content is not available in the form of live lectures or classes", but "at different learning systems and forums" (Dhawan 2020, 7) since 2008, some University departments found it quite easy to shift to this mode of teaching, looking for ways of using it more extensively. However, there was a huge imbalance between the departments in terms of the extent and methods of using the platform, both students and teachers in different departments have had different habits and experiences in using it.

In addition to using Moodle and Zoom, the teaching staff at the University was allowed to use other VoIP applications (Google Classroom, Skype, Viber). 


\section{RECENT STUDIES ON E-LEARNING DURING COVID-19 PANDEMIC}

Measures taken to prevent the spread of the coronavirus disease (school and dormitory closures, physical distancing, confinement, quarantining, travel restrictions) have dramatically affected the lifestyle and well-being of student population worldwide. Recent findings on the impact of the lockdown on the mental health of university students show "an increase in stress levels in the later stages of physical distancing" (Hyseni Duraku and Hoxha 2020, 13) and emphasize the interaction between stress and students' learning skills, time management and student procrastination. Hyseni Duraku and Hoxha's research into the motivation for online learning during the pandemic shows great differences among students: some students enjoyed studying online, while others reported the "lack of motivation and negative attitudes towards learning online" (ibid., 2). As expected, the results confirmed that there was a direct proportion between the level of stress caused by the changes in students' lives due to preventive measures against COVID-19 (e.g. change of residence, confinement, interruptions, family environment, different learning format) and the level of motivation for engaging in online learning: "students who reported that they were not at all motivated to engage in online learning also reported high (moderate to severe) levels of psychological distress, as opposed to students who reported being highly motivated to attend classes online" (ibid., 3). For this reason, students' attitude to online learning during COVID-19 vary. For some students, as confirmed by Hyseni Duraku and Hoxha (2020), online learning is a great opportunity: 1) to save time and money and devote more time to studies, 2) to actively participate in classes and thus increase their level of motivation and their capacity for self-organization which contributes to effective learning, and 3) to draw the attention away from the pandemic and get emotional support from teachers. Other students report on their negative experiences in online learning, most important being: 1) lack of attention due to a change in lesson format and to their psychological state; 2) fluctuation in the level of motivation (higher levels in the first two weeks); 3) heavy workload; 4) distraction by family members; 5) increased use of technology, and 6) bad time management and the procrastination in the learning process (ibid.).

The results of the study by Gonzalez et al. aimed at exploring the effects of COVID-19 confinement on students' performance in higher education confirm that there is "a significant positive effect of COVID-19 confinement on students' performance" (Gonzalez, et al. 2020, 21) even though the courses taught during the confinement implied the same teaching methodology, teachers and the assessment process (the same format of online tests) as in the period before COVID-19. The main reason for the significantly better students' performance was the new learning methodology during the confinement which does not refer to the same/uniform learning methodology adopted by the students during the confinement but to the "general change in the autonomous learning process" (Gonzalez, et al. 2020, 22). As further explained in the study, the confinement period was a completely new scenario which imposed different motivations (rewards) for continuous learning that led to better performance: in order to be sure they are following the course correctly and not missing any important content, or make sure they do not miss the academic year because of the confinement, some students felt the need to work continuously; while for the others, it was their intrinsic responsibility (to contribute to solving the problem the higher education was facing at the time) that made them work harder. The results of the study also indicate positive future trends in students' performance due to a real improvement in students' learning during COVID-19 confinement. 


\section{RESEARCH CONTEXT AND DESIGN}

\subsection{Teaching approaches at FIT and FVA during COVID-19}

English for Specific Purposes (ESP) courses at the University "Mediterranean" are taught during the second (Faculty of Visual Arts - FVA) or the third study year (Faculty of Information Technology - FIT), after the completion of the General English course (B1-B2 level).

In both departments, a number of activities introduced in the ESP course are aimed at encouraging learning autonomy (e.g. creating a video, a wiki, a blog, a website; presenting a portfolio, etc.). As technology is either students' major subject field (FIT students) or an indispensable tool for design software programmes (FVA students), these students are digitally literate which helps them easily acquire the four Cs of the $21^{\text {st }}$ century learning skills: critical thinking, creativity, communication and collaboration. By the time the pandemic started, the students of the FIT had already got used to using Moodle regularly, as support to their classroom learning or part of blended learning. On the other hand, the students of the FVA had not had any experience in online form of teaching: well accustomed to 'art' methods of teaching, i.e. practical individual work aimed at helping students master the skills of using classical and modern digital tools, and to the in-person consultations with the teacher who monitors learners' progress, these students were not familiar with Moodle, nor with any other learning platform.

Regardless of the students' experience or the lack of experience with learning platforms or blended learning, both groups of students were expected to show high attendance at the online classes held via Zoom. At the beginning, we noticed that almost the same students who had attended classes in the real-life classroom were also attending Zoom sessions. Bearing in mind a possible decline in students' motivation due to stress and anxiety caused by the preventive measures against COVID-19, we wanted to encourage students to take a more active participation in virtual classrooms. Before the pandemic, all the teaching materials had been provided by their teacher who had also helped them choose appropriate tools and applications and led them through learning. Now, under the new circumstances caused by the shift to online mode of teaching, these students had to be stimulated to learn more autonomously.

The new, virtual environment imposed a number of changes at the classroom/course level, such as those in the seating arrangement, or those that involve new teaching methods and activities for making teaching more learner-centred, which are usually used to positively affect students' motivation (Anthony 2018). In the new environment, students were allowed to actively participate in Zoom sessions while sitting comfortably on their sofas, or lying in bed instead of sitting at their desks, and were using different online tools and experimenting with new presentation technologies (such as moving from a whiteboard to different applications), which, as an alternative mode of teaching, helped students engage more actively in the teaching process (Dhawan 2020). The social interaction enabled by Zoom, used to create a synchronous learning environment and thus similar to real-life classroom, was another important factor that contributed to improving students' motivation for learning. In order to ensure more intense students' attentiveness and concentration during Zoom sessions, as suggested in an overview of the instructional strategies for online learning (Mahmood 2020), we divided our bigger lectures into smaller building blocks such as smaller units, class discussions and multiple small tasks and had shorter Zoom sessions (40 minutes long). Furthermore, we made sure the 
students were provided with online class recording in case a student missed or did not understand well parts of the lecture.

Bearing in mind that "motivation does not remain constant during the course of months, years or even during a single lesson" when it comes to learning a foreign language and that it "ebbs and flows in complex ways in response to various internal and external influences" (Dörnyei and Ushioda 2011, 6), we tried to implement some of the learning strategies for improving students' motivation suggested by these authors: making learning stimulating and enjoyable (e.g. enriching virtual lessons with topic-related audio/video clips and more engaging class discussions); setting specific learner goals (e.g. improving presentation/ writing skills in 3 weeks); promoting cooperation among the learners (e.g. encouraging better students to work with weaker and give group presentations); creating learner autonomy and promoting self-motivating learner strategies (e.g. allowing students to choose their own topics to be explored and further discussed in virtual class or develop their own ideas for homework assignments related to what is being studied in class).

Despite the differences in the teaching approach, we observed the learning behaviour of our students during the lockdown and noticed that in the same extraordinary situation they reacted differently, probably due to their differences in coping with the new circumstances: some of them were highly enthusiastic about the participation in classes, and some of them, even when they were physically present, showed no willingness for active participation. The enthusiasm mostly came from the feeling that they were attending classes from their homes. On the other hand, students felt they were overloaded with extra work assigned by other teachers, and/or time they had to spend online, which caused their dissatisfaction.

By the time the lockdown started, the students of the FIT had already started doing an independent assignment, i.e. writing wikis, which is the first step to their final task designing a website. They had also done their first mid-term exam. During COVID-19, the students were encouraged to actively participate in Forum which was used for further discussion on the topics mentioned during the Zoom meetings, to collaborate in the group projects and use peer review during the Zoom sessions. The students were reminded of due dates for all assignments via email and News on Moodle.

In order to encourage a more autonomous approach to learning during the lockdown, the students of the Faculty of Visual Arts were asked to do their own research on the topic they thought was relevant for the real-world context and their future working environment, but also present the topic to the group (through Zoom) and create the accompanying glossary. Peer review of the oral presentations given during the Zoom sessions ensured a more collaborative work and social interaction. Active engagement in class discussions, autonomous research and the increased number of homework assignments (twice as big as in the period before the crisis) meant earning more points. Before the lockdown started, the students had also done their first mid-term exam.

The most challenging part of the teaching process, however, was assessment and evaluation of students' progress. Taking into consideration Anthony's claim that "within a course, learners may feel strongly motivated if the instructors directly address issues on a high-stakes test that they must take later" (Anthony 2018, 132), our greatest effort while teaching ESP classes was aimed at providing an ongoing assessment, but also ensuring taskbased learning and dealing with the issues students might find useful in some of the high-test takes they might take later (job interviews, master programme entrance examination, etc.). Therefore, we tried to give priority to formative assessment (quizzes, questioning, assignments, peer assessment of the presentation skills against the checklist; class discussion 
on students' essays against the sample formats, self-assessment of listening skills, etc.) with the purpose of proving constant feedback and ensuring ongoing learning. Though aware of the need to redesign the evaluation test formats to suit the virtual environment, we were concerned about how to create fair testing and ensure students not to cheat in the exams. Online tests were conducted by means of Moodle and Google Classroom which offer a wide range of question types. In order to simulate classroom environment and monitor students' work, we set timing for the test and asked students to be on Zoom during testing. In addition to this, we extended the desktop and asked students to share their screens. This way we were able to follow students' behaviour during the testing on one screen, and their work on the other. We randomly picked students and monitored their actions and writing.

The final exam was done in the classroom, as the situation related to COVID-19 noticeably improved, but also because the Law on Higher Education does not stipulate any other option.

\section{CASE STUdY: LEARNING BEHAVIOUR DURING COVID}

This study aims to explore students' learning behaviour (defined as students' academic participation, students' attitudes and students' performance) in relation to the learning situation (before COVID-19 or during COVID-19 ${ }^{1}$ ). Students' academic participation refers to students' attendance, student engagement in in-class activities and completion of out-ofclass assignments. Students' performance refers to students' results in mid-term tests and final exam. The purpose of the study is to explore potential differences in responsiveness and performance of the same groups of students in different learning environments (before COVID or during COVID). The differences would be determined by comparing students' participation and performance in regular (non-Covid) and extraordinary (during-Covid) situation. By exploring the differences this study aims to give insights into whether virtual classroom provides better environment for continuous learning and better students' performance.

These aims led us to the following hypotheses:

H1: Students' academic participation in virtual environment is higher than in traditional environment due to a different teaching approach, forms of assessment carried out in virtual environment and students' positive response to confinement.

H2: Students' performance in the mid-term test and final exam during the lockdown (spring term 2020) is higher/better than their performance in the mid-term test and final exam during the period before the lockdown (autumn term 2019).

\subsection{Data and feedback collection}

In this study, we adopted a mixed research method approach known as the sequential explanatory design method. Mixed research method is a research design that combines strengths of both qualitative and quantitative approaches. The sequential explanatory design method comprises a quantitative phase followed by a qualitative one. For the quantitative phase, we collected data on students' academic participation and performance,

\footnotetext{
${ }^{1}$ The terms "before COVID" and "during COVID" shall be referred to as non-COVID and COVID, respectively, in this paper
} 
while for the qualitative phase, open-ended questions were conducted and analyzed to explore students' attitudes and to reflect on the numerical results.

In this manner for each student we collected the data presented in Table 1.

Table 1 Data included in the analysis

\begin{tabular}{|l|c|l|}
\hline Variables & Hypothesis & Data set \\
\hline Student id & H1 \& H2 & Students' identification number \\
\hline Participants & H1 \& H2 & $\begin{array}{l}\text { COVID (spring semester) and Non-COVID } \\
\text { (autumn semester) }\end{array}$ \\
\hline Faculty & H1 \& H2 & FIT and FVA \\
\hline Students' attitudes & H1 \& H2 & Interview answers \\
\hline $\begin{array}{l}\text { Student academic participation } \\
\text { in COVID and non-COVID } \\
\text { period }\end{array}$ & H1 & $\begin{array}{l}\text { Attendance and in-class involvement } \\
\text { (COVID and non-COVID period) } \\
\text { Discussion in classes (COVID and } \\
\text { non-COVID period) }\end{array}$ \\
$\begin{array}{l}\text { - Forum (COVID) } \\
\text { Presentation (COVID) } \\
\text { - } \begin{array}{l}\text { Homework (COVID and non-COVID) } \\
\text { Wiki (COVID) } \\
\text { - Blog (non-COVID) } \\
\text { Video (non-COVID) }\end{array}\end{array}$ \\
\hline Mid-term 2 results & H2 & $\begin{array}{l}\text { Mid-term exam results in form of score } \\
\text { (out of 20) }\end{array}$ \\
\hline Final-exam score & H2 & Final exam results in form of score (out of 20) \\
\hline
\end{tabular}

\subsection{Results and discussion}

This study gathered 62 Bachelor students of the FIT and the FVA, University "Mediterranean" Podgorica, Montenegro. All data extracted were analysed using the IBM SPSS tool. Based on the assessment of the data normality, for measuring differences among groups (H1 and H2) parametric (Paired-sample t-test) was used. The significance is measured at a level of $5 \%$ (p-value<.05). The qualitative analysis was performed by means of interview. Sixty-two students participated in the research, 19 from the FVA and 43 from FIT. Twenty-four of these students took part in the interview.

\subsubsection{Data analysis}

In order to check the $\mathrm{H} 1$, we conducted paired-samples T-tests. A paired-samples t-test was conducted to compare academic participation in COVID and non-COVID environment. Paired-sample test showed that there were statistically significant results and that during COVID time students had higher academic participation $\mathrm{M}=5.69, \mathrm{SD}=4.17$, than during non-COVID $\mathrm{M}=4.56, \mathrm{SD}=3.09, \mathrm{MD}=1.12, \mathrm{t}(61)=-2.453 . \mathrm{p}=0.17$. According to the results, we can conclude that $\mathrm{H} 1$ is confirmed.

In order to test $\mathrm{H} 2$, paired-samples T-tests were conducted. A paired-samples t-test was conducted to compare performance in COVID and non-COVID environment. Pairedsample showed that there were statistically significant differences in the final test but not in the mid-term exam. That is why $\mathrm{H} 2$ is partially confirmed. The results are presented in Table 2. 
Table 2 Results of the quantitative analysis

\begin{tabular}{|l|l|c|c|c|c|}
\hline \multicolumn{2}{|c|}{} & Mean & Std. Deviation & $\mathrm{t}(61)$ & $\mathrm{p}$ \\
\hline \multirow{2}{*}{ Pair 1 } & Mid-term exam 2 (autumn) & 8.05 & 1.541 & \multirow{2}{*}{.586} & \multirow{2}{*}{.560} \\
\cline { 2 - 4 } & Mid-term exam 2 (spring) & 7.94 & 1.199 & & \multirow{2}{*}{2.237} \\
\multirow{2}{*}{ Pair 2 } & Final exam (autumn) & 8.69 & 1.615 & \multirow{2}{*}{$0.02{ }^{*}$} \\
\cline { 2 - 4 } & Final exam (autumn) & 8.29 & 1.750 & & \\
\hline
\end{tabular}

\subsubsection{Qualitative analysis and reflection on quantitative}

For the purpose of checking the results of the quantitative analysis and explore students' attitudes we also conducted interviews with 24 students. The questions were divided in two sections: one referring to the academic participation and the other to the performance.

Table 3 Students' answers from the interview

\begin{tabular}{|c|c|c|}
\hline \multicolumn{2}{|c|}{ ACADEMIC PARTICIPATION } & Analysis \\
\hline Q1 & $\begin{array}{l}\text { "What motivated you to } \\
\text { actively participate in online } \\
\text { classes of English } \\
\text { Language?" }\end{array}$ & $\begin{array}{l}\text { All students agreed that the positive factors of } \\
\text { online learning were: saving time and money, } \\
\text { comfort of learning from home, availability of } \\
\text { recorded lectures at any time. } \\
\text { - The students agreed on the following negative } \\
\text { factors: lack of interaction with the teacher } \\
\text { and other students, technical issues, } \\
\text { distraction by family members, lower } \\
\text { concentration, worse understanding during the } \\
\text { online sessions. }\end{array}$ \\
\hline Q2 & $\begin{array}{l}\text { "What was the workload in } \\
\text { English Language course?" }\end{array}$ & $\begin{array}{l}\text { All students agreed that they had almost the } \\
\text { same workload as in the traditional } \\
\text { environment and explained that the teachers' } \\
\text { approach helped them complete all the } \\
\text { assignments. }\end{array}$ \\
\hline Q3 & $\begin{array}{l}\text { "Were you more active in } \\
\text { online classes?" }\end{array}$ & $\begin{array}{l}\text { - Different answers: } \\
\text { - Most students ( } 19 \text { out of } 24 \text { found traditional } \\
\text { learning more appropriate due to better } \\
\text { interaction with a teacher and due to the fact } \\
\text { they were more used to the traditional } \\
\text { learning environment. } \\
\text { - } 3 \text { students did not see any difference in active } \\
\text { participation } \\
\text { - } 2 \text { students were more prone to online learning } \\
\text { (one of them said it was easier to participate } \\
\text { and the other student, who stutters, said he } \\
\text { was not exposed to other students and was } \\
\text { more comfortable in online sessions and the } \\
\text { atmosphere was more relaxing). }\end{array}$ \\
\hline
\end{tabular}




\begin{tabular}{|c|c|c|}
\hline \multicolumn{2}{|c|}{ PERFORMANCE } & Analysis \\
\hline Q1 & $\begin{array}{l}\text { "What are your attitudes to } \\
\text { online testing?" }\end{array}$ & $\begin{array}{l}\text { The students agreed on the following: } \\
\text { - Advantages: simpler, lower pressure, saving } \\
\text { resources, comfort of working from home } \\
\text { - Disadvantages: technical problems (power } \\
\text { cut, bad internet connection), distraction by } \\
\text { family members during the test, inability to } \\
\text { access the platform and send the tests, the } \\
\text { system may bug and the students' answers } \\
\text { may be lost, more demanding) }\end{array}$ \\
\hline Q2 & $\begin{array}{l}\text { "Is online testing better } \\
\text { suitable form of assessing } \\
\text { online learning" }\end{array}$ & $\begin{array}{l}\text { - } 22 \text { out of } 24 \text { students said it was not. The } \\
\text { explained that classroom testing was better } \\
\text { because they prefer the classroom } \\
\text { environment, they have live interaction with a } \\
\text { teacher and online test format is not adequate } \\
\text { for checking their real knowledge } \\
\text { - } 2 \text { out of } 24 \text { students answered they found it } \\
\text { more suitable and easier as the learning is } \\
\text { carried out in virtual environment }\end{array}$ \\
\hline Q3 & $\begin{array}{l}\text { "Was it possible to cheat in } \\
\text { online exams?" }\end{array}$ & $\begin{array}{l}\text { - } 22 \text { students agreed they were aware of the } \\
\text { possibility for cheating but they do not know } \\
\text { whether some students cheated or not }\end{array}$ \\
\hline
\end{tabular}

\section{CONCLUSION AND DISCUSSION}

The extraordinary situation caused by COVID-19 imposed new challenges for both teachers and students. The teachers in all educational institutions were forced to find different ways to adapt to new circumstances and find opportunities to get the best out of themselves and the students. At the end of the lockdown, we conducted a research on 62 students of the FVA and the FIT, University "Mediterranean" Podgorica, Montenegro, to check whether the alternative modes of teaching and assessment applied during the COVID19 period produced a positive change in the students' learning behaviour. Therefore, we focused on comparing two areas, students' academic participation and performance, in two semesters (before and during COVID-19).

Based on the presented results we came to the conclusion that students' participation was significantly higher during the COVID-19 period. Even though we noticed certain fluctuation in active participation of some students in the Zoom classes, as confirmed by the interview with 24 students (see Table 3), the results show that the students' overall academic participation measured through attendance, in-class and out-of-class engagement and completed assignments, was on a much higher level than in the previous semester (before COVID-19). Despite the occasional lack of motivation that some students experienced during the lockdown, the reasons for the positive response might lie in: the teaching approach which urged autonomous learning, continuous work, ongoing assessment, the comfort of working from home, as well as the fact that most of the students, despite the different attitudes to online teaching, wanted to take advantage of the situation by spending their time during COVID-19 more efficiently and successfully, but they also feared they might suffer the consequences for not completing the tasks (they 
might fail exams, miss the study year, etc.). The reasons for the positive response are also indicated in the interview (see Table 3 ).

As for the students' performance, the results showed that there were statistically significant differences in the final test conducted during COVID-19, but not in the midterm exam. This means that the students achieved better results in the final exam in the spring term (COVID-19) than in the autumn (non-COVID) term. On the other hand, their mid-term exam results in both semesters were similar. The reason for better results in the final exam might be the fact that the learning process was conducted in online environment with adapted teaching approaches which encouraged greater academic participation and continuous learning, but also the fact that the final exam was done in the traditional environment. This fact is confirmed by the students' answers in the interview (see Table 3) in which the traditional classroom is described as a much more suitable, reliable and comfortable environment for students' evaluation. Almost the same results obtained in mid-term tests in both semesters may be explained by the fact that despite the greater students' participation in COVID-19 period, which was supposed to lead to better results than in the non-COVID period, the students in COVID-19 period were generally repelled by the online test format, virtual environment and the lack of interaction with the teacher during the evaluation.

Given the fact that this research is based on a small corpus analysis and therefore considered a case study, we believe that the observations presented may be used as a starting point for further research on learning behaviour in extraordinary situation.

\section{REFERENCES}

Anthony, Laurence. 2018. Introducing English for Specific Purposes. Abingdon/New York: Routledge.

Dhawan, Shivangi. 2020. "Online Learning: A Panacea in the Time of COVID-19 Crisis." Journal of Educational Technolog Systems 49(1): 5-22.

Dörnyei, Zoltán, and Ema Ushioda. 2011. Teaching and Researching Motivation. Edinbourgh: Pearson Education Limited.

Gonzalez, T., M. A. de la Rubia, K. P. Hincz, M. Comas-Lopez, L. Subirats, S. Fort, and G. M. Sacha. 2020. "Influence of COVID-19 confinement in students performance in higher education.” arXiv. 20 April. https://arxiv.org/ftp/arxiv/papers/2004/2004.09545.pdf.

Hyseni Duraku, Zamira, and Linda Hoxha. 2020. "The impact of COVID-19 on higher education: A study of interaction amongstudents' mental health, attitudes toward online learning, study skills, andchanges in students' life." Researchgate. 26 May. https://www.researchgate.net/publication/341599684_The_impact_of_COVID19_on_higher_education_A_study_of_interaction_among_students'_mental_health_at titudes_toward_online_learning_study_skills_and_changes_in_students'_life.

Mahmood, Samreen. 2020. "Instructional Strategies for Online Teaching in COVID-19 Pandemic." Wiley Online Library. 03 May. https://onlinelibrary.wiley.com/doi/full/ $10.1002 / \mathrm{hbe} 2.218$

United Nations. 2020. Policy Brief: Education during Covid-19 and beyond. United Nations.

Žižek, Slavoj. 2020. Pandemic! COVID-19 Shakes the World. New York/London: OR Books. 